\title{
On the measurement of solids circulation rates in interconnected fluidized beds: comparison of different experimental techniques
}

\section{Citation for published version (APA):}

Medrano Jimenez, J. A., Nordio, M. L. V., Manzolini, G., van Sint Annaland, M., \& Gallucci, F. (2016). On the measurement of solids circulation rates in interconnected fluidized beds: comparison of different experimental techniques. Powder Technology, 302, 81-89. https://doi.org/10.1016/j.powtec.2016.08.035

\section{Document license:}

TAVERNE

DOI:

10.1016/j.powtec.2016.08.035

Document status and date:

Published: 01/01/2016

\section{Document Version:}

Publisher's PDF, also known as Version of Record (includes final page, issue and volume numbers)

\section{Please check the document version of this publication:}

- A submitted manuscript is the version of the article upon submission and before peer-review. There can be important differences between the submitted version and the official published version of record. People interested in the research are advised to contact the author for the final version of the publication, or visit the $\mathrm{DOI}$ to the publisher's website.

- The final author version and the galley proof are versions of the publication after peer review.

- The final published version features the final layout of the paper including the volume, issue and page numbers.

Link to publication

\footnotetext{
General rights

- You may freely distribute the URL identifying the publication in the public portal. follow below link for the End User Agreement:

www.tue.nl/taverne

\section{Take down policy}

If you believe that this document breaches copyright please contact us at:

openaccess@tue.nl

providing details and we will investigate your claim.
}

Copyright and moral rights for the publications made accessible in the public portal are retained by the authors and/or other copyright owners and it is a condition of accessing publications that users recognise and abide by the legal requirements associated with these rights.

- Users may download and print one copy of any publication from the public portal for the purpose of private study or research.

- You may not further distribute the material or use it for any profit-making activity or commercial gain

If the publication is distributed under the terms of Article 25fa of the Dutch Copyright Act, indicated by the "Taverne" license above, please 


\title{
On the measurement of solids circulation rates in interconnected fluidized beds: Comparison of different experimental techniques
}

\author{
J.A. Medrano a , M. Nordio a,b , G. Manzolini b , M. van Sint Annaland ${ }^{\text {a }}$, F. Gallucci a,* \\ a Chemical Process Intensification, Department of Chemical Engineering and Chemistry, Eindhoven University of Technology, De Rondom 70, 5612 AP Eindhoven, The Netherlands \\ b Group of Energy Conversion Systems, Department of Energy, Politecnico di Milano, Via Lambruschini 4, 20156 Milano, Italy
}

\section{A R T I C L E I N F O}

\section{Article history:}

Received 14 March 2016

Received in revised form 2 August 2016

Accepted 15 August 2016

Available online 16 August 2016

\section{Keywords:}

Circulating fluidized bed reactor

PIV/DIA

Pressure sensors

Solids circulation rate

\begin{abstract}
A B S T R A C T
Membrane assisted Chemical Looping Reforming (MA-CLR) is a novel concept recently proposed for efficient hydrogen production with integrated $\mathrm{CO}_{2}$ capture. This novel technology is based on the circulation of a solid (an oxygen and heat carrier) between two different reactors, an air reactor and a membrane assisted fuel reactor. The solids circulation rates (SCR) between the two reactors determine the oxygen and heat transfer rate and temperature difference between the reactors and hence the overall performance of the new concept. However, the prediction of the SCR is still based on empirical correlations while many different techniques have been used in the literature to measure it. In this work a comparison of three different experimental techniques for the SCR is presented. A pseudo 2D interconnected circulated fluidized bed system has been constructed and the SCR have been measured using an optical technique, a pressure difference technique and a particles extraction technique. The three methods have been compared for different experimental conditions by varying superficial gas velocities, particle diameter and particle type. Results show that the SCR can be well predicted with the pressure drop method as the results are in good agreement with both the optical technique and the particle extraction technique for both spherical particles and non-spherical particles. The fact that the optical and pressure methods are not intrusive represents the main advantage for both. However, while the optical technique gives more information on the distribution of the solids hold-up along the riser of the chemical looping system, it can only be applied to 2D systems as optical access is required. On the other hand, the pressure drop technique is much cheaper and easier to be applied and can also be used for 3D high temperature systems.
\end{abstract}

(c) 2016 Elsevier B.V. All rights reserved.

\section{Introduction}

Climate change has been deeply investigated and analyzed by many researchers and some relations to the anthropogenic greenhouse gas emissions associated with the large use of fossil fuels have been proposed. Among these gases $\mathrm{CO}_{2}$ is indicated as the most important component responsible for global warming. Problems and consequences of the extensive emissions of $\mathrm{CO}_{2}$ to the atmosphere have already being reviewed and continuously reported by the Intergovernmental Panel on Climate Change (IPCC) [1,2] and the International Energy Agency (IEA) [3].

The development of renewable and non-polluting energy resources has been proposed as the main solution for the reduction of pollution level caused by those conventional fuels. However, this strategy cannot be implemented in short term and cannot totally substitute traditional processes based on fossil fuels. During the transition to these novel technologies based on renewable sources, it can be strategic improving

\footnotetext{
* Corresponding author.

E-mail address: f.gallucci@tue.nl (F. Gallucci).
}

traditional processes based on fossil fuels, especially for those with high $\mathrm{CO}_{2}$ emissions (such as combustions for power generation).

A way to increase the process efficiency while allowing $\mathrm{CO}_{2}$ free combustions is the use of hydrogen [4]. Hydrogen is an excellent energy carrier and is considered as an alternative fuel since it can be generated from clean and green sources and the only product of combustion is water [5]. However, nowadays a very low percentage of hydrogen is produced from renewable sources through water electrolysis while the rest is still derived from fossil fuels [4] with consequent $\mathrm{CO}_{2}$ emissions. A strategy proposed for reducing emissions is the $\mathrm{CO}_{2}$ capture and storage (CCS) technology which could provide a solution to mitigate environment impacts and allows a longer exploitation of fossil energies until renewable energy technologies are ready for application. CCS is a technology where a highly concentrated stream of $\mathrm{CO}_{2}$ is produced in the industrial process and it is subsequently stored underground $[1,6-8]$.

Among the different concepts proposed for the implementation of CCS in the process industry, the development of Chemical Looping for fuel Combustion (CLC) or fuel Reforming (CLR) and membrane reactors seem to allow very low energy penalties for the $\mathrm{CO}_{2}$ capture [9-14]. 
Chemical Looping reforming refers to the technology where a solid with high oxygen capacity (called oxygen carrier) circulates between two interconnected reactors, transporting oxygen and heat between the two reactors [15-17]. These reactors work under different atmospheres where different reactions take place. One reactor is the so called fuel reactor, where reforming of a fuel takes place. The heat of reaction (and oxygen) is supplied by the oxygen carrier, which is thus reduced. The reduced solid is then transferred to a second reactor named air reactor. In this second reactor the solid is in contact with air providing the oxidation of the solid, which is again transferred back to the fuel reactor. Thus the global system behaves like a cycle where the fuel and air are fed into the system but never mixed in the same unit. This implies that $\mathrm{CO}_{2}$ produced in the fuel reactor through fuel conversion will not be diluted in nitrogen fed in the air reactor. In this situation a highly concentrated stream of $\mathrm{CO}_{2}$ is achieved suitable for CCS without requiring energy intensive separation steps downstream the reactor.

A good performance of the system is only achieved when optimizing many different parts that play an important role in Chemical Looping. They include the activity of the oxygen carrier, the type of fuel, the reaction conditions in both reactors and the solids circulation rates (SCR) between the two reactors. Among these characteristics, a proper measurement of the SCR is essential for controlling the residence time of the solid, heat fluxes and the conversion rates of the oxygen carrier, whereas the SCR strongly depends on the particle properties, gas velocities and total solids inventory.

Different techniques have been proposed in literature for the measurement of the SCR in such systems. They consist of invasive and non-invasive techniques and include the direct measurement of descending solid mass [18,19], the use of optical fiber probes [20,21], fiberglass spirals [22] or pressure transducers along the height of the riser to measure the solids holdup $[18,23,24]$. While the first three methods need a high maintenance and become expensive and, in the case of probes, also intrusive, the pressure transducers method is easier but tends to overestimate the real SCR and requires proper calibration. Therefore, it becomes difficult to define the best method available for the measurement of the SCR.

This work aims at providing more insight into the relative performance of different techniques for the measurement of SCR for Chemical Looping. The work focuses on the comparison of three different methods: first the solids circulation rates are measured by collecting particles during a certain time in the downcomer from the riser. Subsequently, pressure transducers are used along the riser in order to determine the solids holdup and solids velocities and, thus the SCR. Finally, a novel optical technique has been used for a proper estimation of the SCR and validation of the pressure transducer method. This last technique is a non-intrusive experimental method which combines Particle Image Velocimetry (PIV) for a proper estimation of particle velocities with Digital Image Analysis (DIA) for the determination of the solids holdup at any position in the bed, while their combination provides information on the solid fluxes of the downcomer particles from the riser to the fuel reactor. The PIV/DIA technique can, however, only be applied to pseudo 2D columns because of the required visual access.

Different experimental conditions affecting the SCR have been considered in this study, and in particular, the solids inventory, particle diameter and particle density have been varied.

In this study the PIV/DIA technique has been used for the first time for the non-invasive measurement of the SCR and as validation of the measurement by the pressure sensors method. This validation is very important as the pressure measurement can be easily applied to 3D (and high temperature) fluidized beds.

This work presents first the reactor used during the experimental investigation, which represents an ideal 2D slice of a reactor used in the literature for biomass gasification which consists of a concentric riser in the fuel reactor. Subsequently, the three methods used in this work are explained in detail as well as the experimental conditions used in the study. Afterward, the main results and their discussion are given and the main conclusions highlighted.

\section{Experimental methods}

\subsection{Description of the setup}

A pseudo 2D ( $1.5 \mathrm{~cm}$ in depth) internally circulating bed column was adopted to allow visual inspection for PIV/DIA measurements. The pseudo-2D column has a total height of $220 \mathrm{~cm}$ and consists of three different columns, one internal and two external ones. The internal column is a riser reactor and represents the air reactor in Chemical Looping systems, while the two external columns operated in the bubbling regime represent the fuel reactor in Chemical Looping. The riser is $202 \mathrm{~cm}$ in height and $7.3 \mathrm{~cm}$ in width and operates in the fast fluidization regime. The riser drives the solids circulation when operated above the terminal velocity of the particles. Particles circulate from the top of the riser to the external columns, which are $7.0 \mathrm{~cm}$ in width. Solids circulate from the bottom of the external columns to the riser through two orifices with an internal diameter of $1.5 \mathrm{~cm}$ placed $15.2 \mathrm{~cm}$ above the distributor of the central column. The fact that a high pressure drop is created at these holes (the bed near the holes behaves like a moving bed) avoids gas leakage from the fuel reactors to the riser and vice versa. On top of the riser, an impact element reduces the velocity of the particles and gas is forced to follow a trajectory out of the reactor while particles fall to a chamber connected to the fuel reactors through a $2.0 \mathrm{~cm}$ hole where particles move from the riser to the fuel columns. The fact that solids accumulate in this chamber near the holes avoids gas leakage from the fuel reactor to the riser line. A schematic representation of the setup used in this work is depicted in Fig. 1.

For all experiments, air is used as inlet gas in each column and is fed through a porous plate with a mean pore size of $40 \mu \mathrm{m}$. The front wall of the bed is made of glass in order to give visual access to capture images while the background wall is anodized aluminum (black) to enhance particle/bubble detection when using optical techniques like PIV/DIA. As a reference case, a solids inventory of $2 \mathrm{~kg}$ of glass bead particles (Geldart B) with a particle size distribution of 400-600 $\mu \mathrm{m}$ and a density of $2500 \mathrm{~kg} / \mathrm{m}^{3}$ is used. The minimum fluidization velocity $\left(\mathrm{u}_{\mathrm{mf}}\right.$ ) of these particles is $0.21 \mathrm{~m} / \mathrm{s}$ (as measured by the standard pressure drop method), while their terminal velocity is $2.84 \mathrm{~m} / \mathrm{s}$ as calculated from the correlation by Haider and Levenspiel [25]. For all the particles used in this work, their minimum fluidization velocity and terminal velocity are always calculated prior to the experiments.

The inlet gas stream in the riser is controlled by a $0-1000 \mathrm{~L} / \mathrm{min}$ mass flow controller, while the inlet gas flow rates in the fuel columns are controlled by two $0-50 \mathrm{~L} / \mathrm{min}$ mass flow controllers, all supplied by Brooks Instruments. Water tanks are used in each inlet line to humidify the air in order to prevent electrostatic charging of the particles. The base case used in this work is reported in Table 1. For a proper description of the SCR, experimental conditions have been modified, including gas flow rates, solids inventories and particle diameter and density as stated in Table 2. Furthermore, the developed methods have also been extended to non-spherical particles, where the determination of the SCR becomes more difficult due to the lack of homogeneity as compared to spherical beads. In this work, the particle sphericity has been measured for non-spherical particles using an Expert Shape Quantachrome machine.

\subsection{Solids circulation rate measurements}

\subsubsection{Particle extraction method}

The performance of the reactor is strongly affected by the solids circulation rate between the riser and fuel reactor, which also determines the temperature difference between the two reactors. A stable solids circulation is required in Chemical Looping processes to provide the right amount of oxygen and hence heat in the fuel reactor. To study this 


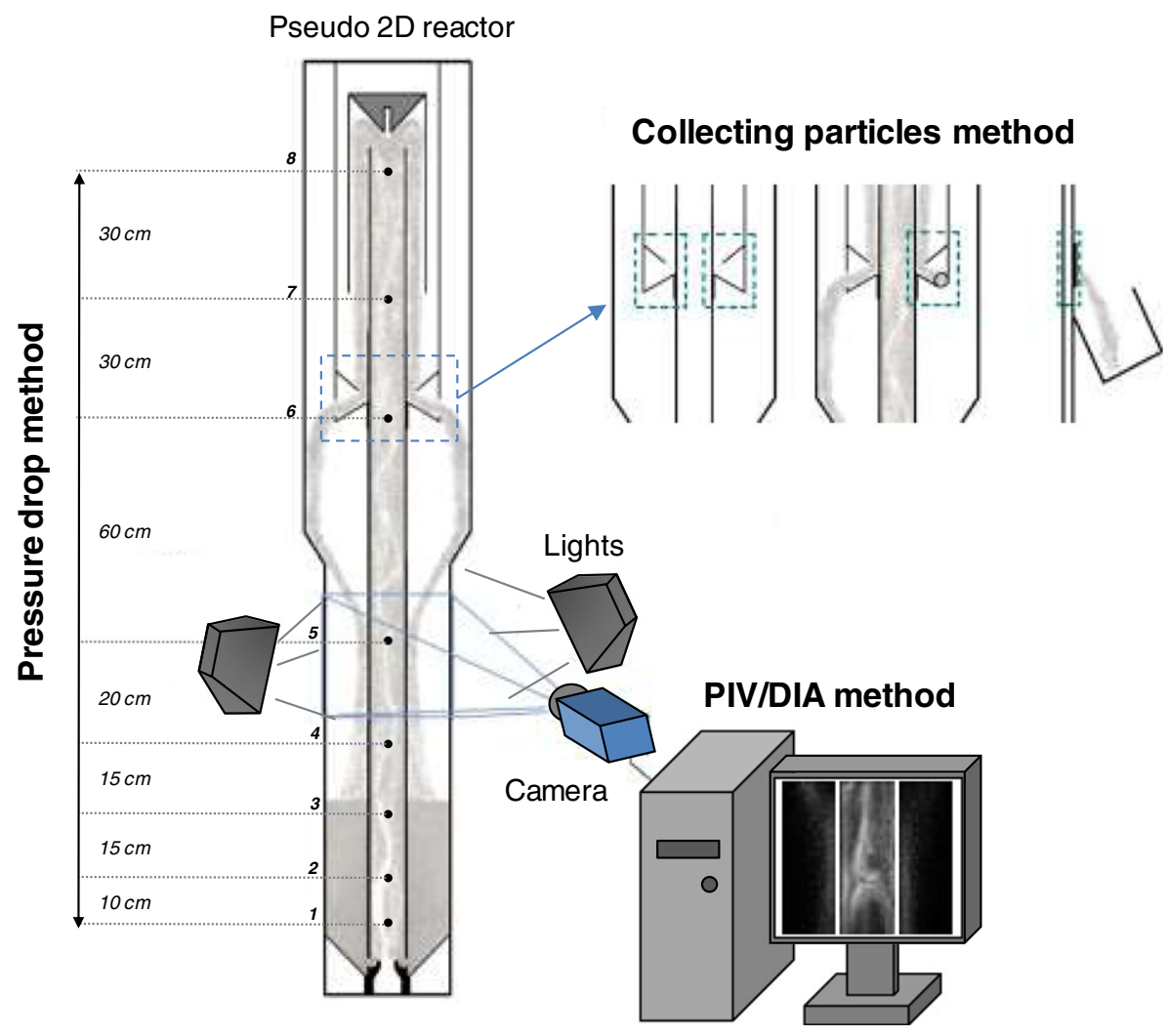

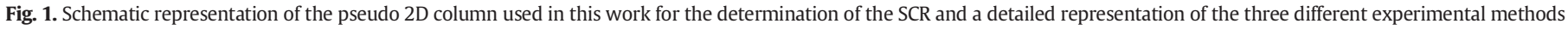
investigated.

phenomenon in the pseudo 2D column, two windows with holes transferring particles from the riser to the fuel columns have been designed and installed. Particle collection is performed by the particles transferred from the riser column to the fuel columns. These windows are displayed in Fig. 1 and the SCR can be obtained by measuring the solids accumulation with time.

The procedure for the measurement is explained as follows: before starting the measurement, the gas velocity in the riser is maintained below its terminal velocity, thus particles remain in the riser. Then the velocity in the riser is increased to the set point required for each experiment reported in Table 2 and the timer is started when particles exit through the hole and get collected in a bucket. After a short time (see the following section for more details), the inlet gas velocity in the riser is reduced below the terminal velocity and the timer is stopped when the last particles pass through the hole.

These measurements are carried out for a short period of time (in the order of 15-20 s) in order to avoid too high disturbance of the system. In fact, the total solids inventory of this type of systems is crucial and determines the solids circulation pattern and solids circulation

Table 1

Experimental conditions selected for the reference case in this study.

\begin{tabular}{|c|c|c|c|c|}
\hline Parameter & Abr. & Dimensions & Fuel column & Air column \\
\hline Particles & - & - & \\
\hline particle diameter & $d_{p}$ & {$[\mathrm{~m}]$} & \multicolumn{2}{|c|}{$5.00 \cdot 10^{-4}$} \\
\hline particle density & $\rho_{s}$ & {$\left[\mathrm{~kg} / \mathrm{m}^{3}\right]$} & \multicolumn{2}{|c|}{2500} \\
\hline inlet gas & - & - & Air & Air \\
\hline gas density & $\rho_{g}$ & {$\left[\mathrm{~kg} / \mathrm{m}^{3}\right]$} & 1.184 & 1.184 \\
\hline Dynamic viscosity & $\mu_{g}$ & {$[\mathrm{~Pa} \cdot \mathrm{s}]$} & $1.79 \cdot 10^{-5}$ & $1.79 \cdot 10^{-5}$ \\
\hline Superficial gas velocity & $u_{g}$ & {$[\mathrm{~m} / \mathrm{s}]$} & 0.32 & 2.94 \\
\hline Gas flow rate & $\mathrm{F}$ & {$[\mathrm{Ln} / \mathrm{min}]$} & $1.66 \mathrm{u}_{\mathrm{mf}}$ & $15 \mathrm{u}_{\mathrm{mf}}$ \\
\hline Solids Inventory & SI & {$[\mathrm{kg}]$} & \multicolumn{2}{|c|}{2} \\
\hline Sphericity & $\emptyset$ & {$[-]$} & \multicolumn{2}{|c|}{1} \\
\hline
\end{tabular}

rates between both columns. The total amount accumulated for the measurement of solids circulation is relatively low compared to the solids inventory, so that the system in not affected. For every case, results considered for the solids circulation rate are obtained through an average of, at least, 15 measurements.

\subsubsection{PIV/DIA method}

The technique is based on recording images with a high speed camera and their subsequent analysis based on cross correlation methods. In this study a Dantec Dynamics Flowsense EO $16 \mathrm{M}$ camera is used for PIV-DIA analysis in the 2D column, which provides a maximum resolution of $4872 \times 3248$ pixels. A software package (Dynamic Studio) is used to adjust the settings of the recordings and post process the pictures. Pictures are taken in double frame mode, i.e. two images are taken with a very short interval $(0.5 \mathrm{~ms})$, followed by a longer interval $(0.5 \mathrm{~s})$ before the next two pictures are recorded. In this way, the two consecutive images can be analyzed together in order to gather the information of the instantaneous solid circulation rates, while the average of many double frames is used to calculate the time averaged solids circulation rates. As depicted in Fig. 1, two LED lights are used for homogeneous illumination of the bed. A control box connected to the computer triggers the camera shutter, while a resolution of 3 pixels per particle is used during the recordings, always with 8 bits depth for double frame mode.

For the measurement of the SCR with this technique, only a part of the reactor is recorded. This area is located at a height of $80 \mathrm{~cm}$ from the bottom of the column and includes its entire width. The size of this area is $20 \mathrm{~cm}$ in height and $23 \mathrm{~cm}$ in width and its main characteristic is that all solid phase observed in the fuel columns are moving downwards, thus more accurate velocity profiles, and hence SCR, can be obtained. In order to obtain better results, the three regions captured (one riser and two fuel columns) are analyzed separately. A schematic representation of the method is depicted in Fig. 1. 
Table 2

List of all experimental conditions used in this work and investigated using the different experimental techniques.

\begin{tabular}{|c|c|c|c|c|c|c|c|}
\hline Experiment & Solids inventory $(\mathrm{SI})[\mathrm{kg}]$ & Particles & $d_{p}[\mu \mathrm{m}]$ & $\rho_{p}\left[\mathrm{~kg} / \mathrm{m}^{3}\right]$ & $\emptyset[-]$ & $\mathrm{U}_{\mathrm{FR}} / \mathrm{U}_{\mathrm{mf}}$ & $\mathrm{U}_{\mathrm{AR}} / \mathrm{U}_{\mathrm{mf}}$ \\
\hline 1 & 2.0 & Glass beads & 500 & 2500 & 1 & 1.66 & 15 \\
\hline 2 & 2.0 & Glass beads & 500 & 2500 & 1 & 1.66 & 17 \\
\hline 3 & 2.0 & Glass beads & 500 & 2500 & 1 & 1.66 & 13 \\
\hline 4 & 2.0 & Glass beads & 500 & 2500 & 1 & 1.30 & 15 \\
\hline 5 & 2.0 & Glass beads & 500 & 2500 & 1 & 2.00 & 15 \\
\hline 6 & 2.25 & Glass beads & 500 & 2500 & 1 & 1.66 & 15 \\
\hline 7 & 2.5 & Glass beads & 500 & 2500 & 1 & 1.66 & 15 \\
\hline 8 & 2.0 & Glass beads & 250 & 2500 & 1 & 2.00 & 24 \\
\hline 9 & 2.25 & Glass beads & 250 & 2500 & 1 & 1.70 & 24 \\
\hline 10 & 2.5 & Glass beads & 250 & 2500 & 1 & 1.40 & 24 \\
\hline 11 & 2.25 & Glass beads & 388 & 2500 & 1 & 1.66 & 15 \\
\hline 12 & 2.25 & Glass beads & 388 & 2500 & 1 & 1.66 & 16 \\
\hline 13 & 2.25 & Glass beads & 388 & 2500 & 1 & 1.66 & 17 \\
\hline 14 & 2.0 & Sand & 460 & 2600 & 0.75 & 1.35 & 14 \\
\hline 15 & 2.0 & Sand & 460 & 2600 & 0.75 & 1.35 & 14 \\
\hline 16 & 2.0 & Sand & 460 & 2600 & 0.75 & 1.35 & 15 \\
\hline 17 & 1.3 & Activated alumina & 510 & 1135 & 0.776 & 1.2 & 14 \\
\hline 18 & 1.3 & Activated alumina & 510 & 1135 & 0.776 & 1.4 & 14 \\
\hline 19 & 1.3 & Activated alumina & 510 & 1135 & 0.776 & 1.2 & 15 \\
\hline
\end{tabular}

Images recorded are subsequently analyzed starting with PIV. This technique gives information on the instantaneous flow velocity across a planar area. The software used in this work for PIV (Davis 8.0) splits the images into interrogation areas and then applies cross correlation algorithms in order to compute the most probable displacement of the solids confined in that interrogation area. All vectors in the interrogation areas are plotted and the instantaneous macroscopic flow pattern is obtained.

For more accurate results, iterations are done using multi-pass options with different interrogation area sizes. For this work the procedure selected starts with a first pass in an initial interrogation area of $128 \times 128$ pixels that calculates a reference vector field for the next pass. In the second pass, the interrogation area is decreased to $64 \times 64$ pixels and $50 \%$ overlapping between them. This overlap determines then the real grid size of the vector field. By multi-pass options the most likely vector displacement can be easier calculated by the software. PIV only accounts for the particles that are inside the interrogation zone in a 2D plane. Therefore particles that move out of interrogation zone are not taken into account. The error caused by this drawback is minimized by a short time interval between the two pictures. Double frame mode minimizes this error by taking two consecutive images with a very short interval (e.g. $0.5 \mathrm{~ms}$ ).

PIV analysis only provides information on the particle velocities. To determine the solids flux profiles another post-processing technique is used on the recorded images: Digital Image Analysis (DIA). DIA is an in-house software developed with the image processing toolbox in Matlab. An image is divided into interrogation zones where the normalized pixel intensity in each zone is used as primarily tool to compute the bed porosity. The values obtained represent the results of $2 \mathrm{D}$ solids fraction measurements, which are used to predict the 3D solids hold up of the bed. In this case the 2D pixel intensity could be correlated to the 3D porosity using the correlation suggested by de Jong et al. [26], which was developed for fluidized beds. However, the solids hold-up in this system is much lower than in fluidized beds, thus a new correlation was developed to determine reliable 3D solids hold up values from the planar 2D intensity profiles.

To correct for inhomogeneous lighting, the bed is filled with particles (corresponding to the experimental case) and images are taken of the fixed bed, which is subsequently used as background for normalization of every single image of the experiment. In this method the lighting for the background image and the experiments should be exactly the same (i.e. the camera and LED light should be exactly in the same position). This correction is depicted in Fig. 2, where the average histograms of two different recordings in the fuel column (right side) are depicted before and after normalization by the fixed bed image. Both histograms correspond to operation conditions of experiment 8 (as reported in Table 2) but with completely different initial illuminations. In Fig. 2, it is observed how for different illuminations, the fixed bed background correction method is able to normalize the intensities, which leads to good reproducibility of the measurements. For the riser, which is less
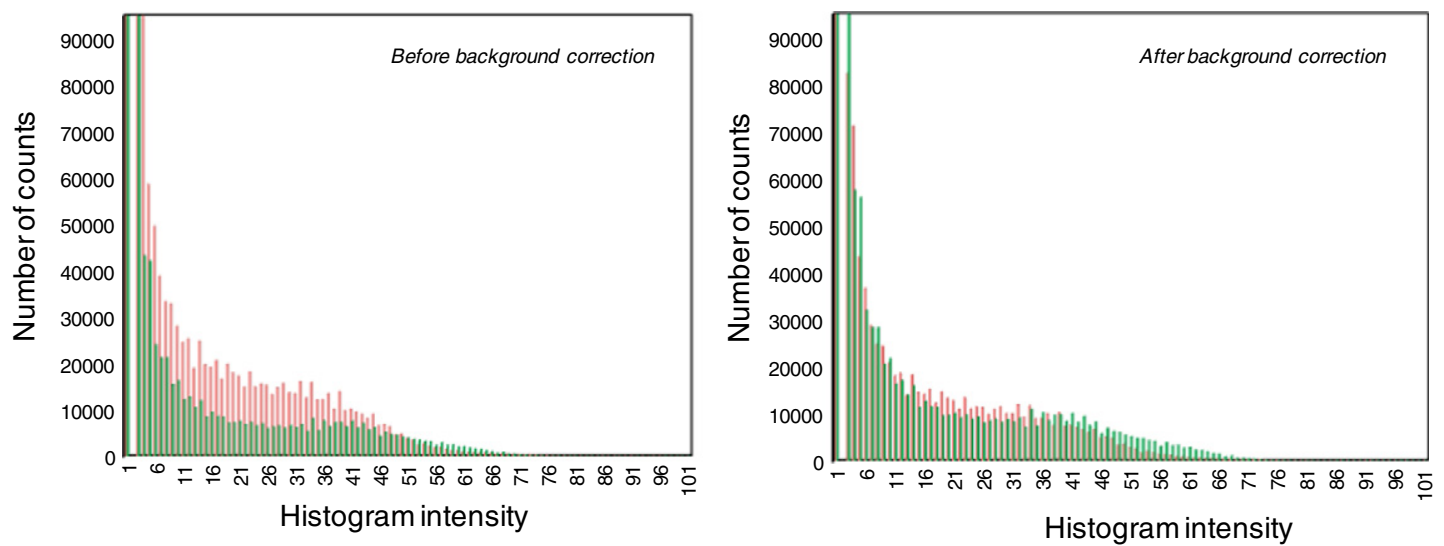

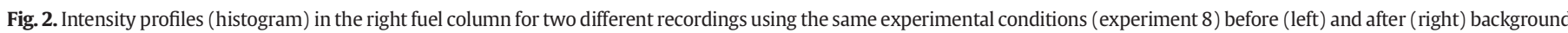
correction. 
diluted than the fuel columns, the background image used for the correction of inhomogeneous lighting is obtained by averaging all images of the recorded experiment, which represents a dynamic background determination. Subsequently, every image is normalized by the subtraction of this average background image.

Once images have been normalized and corrected for inhomogeneous lighting, a reliable correlation between the normalized pixel intensity (2D solids fraction) and the actual porosity (3D solids fraction) is required. In such diluted systems like the ICFBR, a linear correlation between the intensity and porosity is proposed (Eq. (1)). The value of $A$ has been first fitted based on the SCR measured by collecting particles for the first five experiments and has subsequently been applied for all the experiments depicted in Table 2. Since the background correction method is different for the fuel columns and the riser, different fitted values apply. For all cases the SCR is calculated by averaging the actual solid fluxes measured through the combination of the velocity determined with PIV and the solids hold-up determined with DIA at every axial position in the image.

$\varepsilon_{3 D}=A \varepsilon_{2 D}$

The value obtained for $A$ in the fuel columns is 0.049 , whereas in the riser column, where a fixed bed background image is not used but a dynamic background instead, the encountered value of $A$ is 0.032 .

\subsubsection{Pressure transducers method}

The third method aims at determining the total pressure drop in the riser $\left(\Delta P_{\text {riser }}\right)$ between the top and bottom parts of the column. This method allows the estimation of the solids circulation rates in the riser as a function of the local solids holdup measured and the calculated particle velocity. For a proper measurement of the SCR using the pressure drop method the location of the pressure transducers is very important in order to get a good description of the behavior of the bed. These pressure transducers have been located at specific positions in the bed as indicated in Fig. 1.

The method is based on the assessment of solids circulation rates from the particle velocity and solids holdup according to the Eq. (2).

$S C R=u_{P} \varepsilon_{S} A_{c} \rho_{S}$

where $u_{p}$ is the particle velocity, $\rho_{s}$ the density of the particle, $\varepsilon_{s}$ the solids holdup and $A_{c}$ the cross-sectional area of the riser.

To calculate the solids holdup and particle velocity, the Richardson and Zaki model for a mono-dispersed suspension in a system through the Bernoulli equation is used $[24,27,28]$. The main assumptions of the system are:

- The system consists of spherical particles of common specific gravity with a relatively narrow size distribution which can be reduced to an average characteristic size.

- There is no interaction of any kind between the particles, except hydrodynamic effects through the fluid.

- The relative positions of the particles in the cloud are completely random, without any segregation.

- The effect of the column walls is neglected.

The equations describing the system are defined by Eqs. (3) and (4):

$$
\begin{aligned}
& u_{P=} \frac{u_{g}}{\left(1-\varepsilon_{S}\right)}-u_{t}\left(1-\varepsilon_{S}\right)^{n-1} \\
& \frac{p_{2}-p_{1}}{\rho_{R}}-g\left(h_{2}-h_{1}\right)=4 F \frac{L}{D} \frac{1}{2}\left(u_{g}+u_{P}\right)^{2}
\end{aligned}
$$

Where $F$ is the Fanning frictional factor, $u_{g}$ the superficial gas velocity, $u_{t}$ the terminal velocity of particles, $p_{2}-p_{1}$ is the total pressure drop in the riser and $\rho_{R}$ the density in the riser, which is calculated as in Eq.
(5), while the exponential factor $n$ can be determined by the Eq. (6) using the $R e$ of the particle at the terminal velocity $\left(R e_{t}\right)$ :

$\rho_{R}=\rho_{S} \varepsilon_{S}+\rho_{G} \varepsilon_{G}$

$n=\left(4.45+18 \frac{d_{p}}{D}\right) R e_{t}^{-0.1}$

The terminal particle velocity is based on the equation (Eq. (7)) for spherical particle [29]:

$u_{t}=\left(\frac{4 d_{p}\left(\rho_{s}-\rho_{g}\right) g}{3 \rho_{g} C_{D}}\right)^{\frac{1}{2}}$

where $C_{D}$ is the drag coefficient, $\varepsilon_{s}$ and $\varepsilon_{g}$ are the porosity of the solid and of the gas respectively, and $\rho_{s}$ and $\rho_{g}$ the densities of particle and gas phases. $C_{D}$ is calculated according to the Eq. (8) [29] where $R e_{p}$ is the Re number of the particle:

$C_{D}=\frac{24}{R e_{p}}\left(1+0.14 R e_{p}^{0.7}\right) \quad$ for $0.1<R e_{p}<1000$

To calculate the frictional factor the Re number (Eq. (9)) shows that for all conditions there is a turbulent regime.

$\operatorname{Re}=\frac{\rho u_{g} D}{\mu}>2300$

Therefore the Colebrook-White equation (Eq. (10)) is used [6,30]:

$\frac{1}{\sqrt{f}}=1.14-2 \log _{10}\left(\frac{\lambda}{D}+\frac{9.35}{\operatorname{Re} \sqrt{f}}\right) \quad$ for $\operatorname{Re}>4000$

where $f$ is the Darcy frictional factor that is defined as 4 times the Fanning frictional factor and $\lambda$ is the roughness of anodized aluminum, which is the material of the back plate of the riser $\left(1 \cdot 10^{-3} \mathrm{~m}\right) . D$ is the hydraulic diameter for internal convection in the riser and is calculated through Eq. (11), with $a$ and $b$ representing the width and depth of the section respectively.

$D=\frac{2 a b}{a+b}$

For the case of non-spherical particles, the terminal velocity is modified and it is adjusted as indicated by Haider and Levenspiel [25], who implemented the equation suggested by Turton and Clark [31]. Eqs. (12)-(14) show the procedure to determine the terminal velocity for non-spherical particles introducing the dimensionless particle diameter $\left(d_{p}^{*}\right)$, and the dimensionless terminal velocity of the particles $\left(u_{t}^{*}\right)$.

$d_{p}^{*}=d_{p}\left[\frac{\rho_{g}\left(\rho_{s}-\rho_{g}\right) g}{\mu^{2}}\right]^{1 / 3}$

$u_{t}^{*}=\left[\frac{18}{\left(d_{p}^{*}\right)^{2}}+\frac{2.335-1.744 \phi}{\left(d_{p}^{*}\right)^{0.5}}\right]^{-1}$

$u_{t}=u_{t}^{*}\left[\frac{\rho_{g}^{2}}{\mu\left(\rho_{s}-\rho_{g}\right) g}\right]^{-1 / 3}$ 


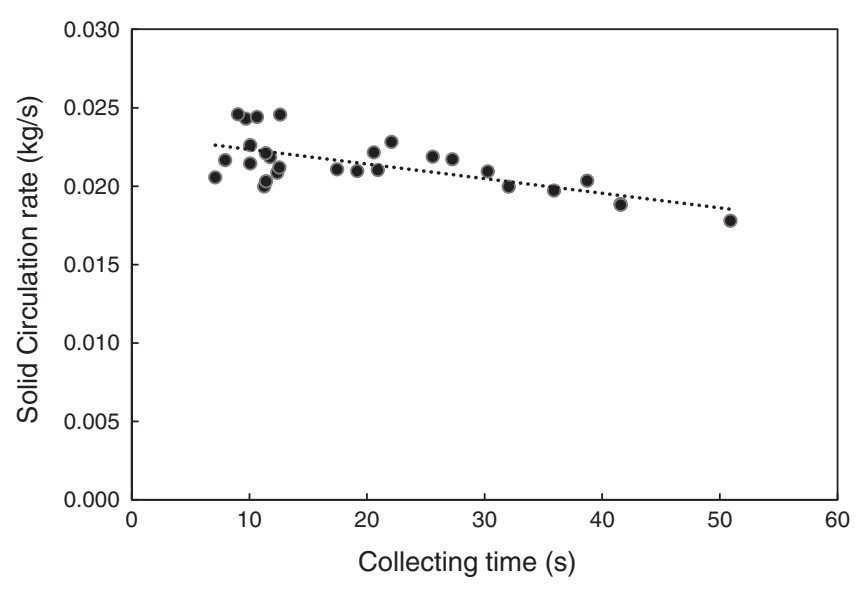

Fig. 3. Influence of the collecting time on the solids circulation rates for Experiment 1.

\section{Results and discussion}

\subsection{Experimental solids circulation rates by collecting particles.}

Before comparing the solids circulation rates measured with the different techniques, it is important to assess the reproducibility of the measurements when collecting particles. A long collection time might lead into an important modification of the hydrodynamics in the column because of the change in solids inventory with a corresponding decrease in the solids circulation rates. This effect has been verified by collecting particles for different collection times in the right column for the conditions of Experiment 1 (reference case). The measured SCR are presented in Fig. 3, showing indeed a reduction in the SCR for longer collecting times. Based on these results, it was decided to select a collecting time such that the amount collected does not exceed $>10 \%$ of the total solids inventories for the experiment (viz. around $10 \mathrm{~s}$ for the reference case presented in Fig. 3). This methodology is subsequently applied to all the other experiments.

The measured SCR for the different experiments are reported in Table 3 for both the left and right fuel columns. For all the cases the measurements have been repeated at least 15 times to increase the measurement accuracy. The standard deviation over the measurements is also provided in the table, indicating a relatively low error. It can be noted that the SCRs are strongly affected by the superficial gas velocity

Table 3

Experimental SCR measured by collecting particles transported from the riser to the fuel column for the different experiments and their standard deviation over the measurements.

\begin{tabular}{|c|c|c|c|c|}
\hline \multirow[b]{2}{*}{ Experiment } & \multicolumn{2}{|c|}{ Left Column } & \multicolumn{2}{|c|}{ Right Column } \\
\hline & $\mathrm{SCR}(\mathrm{g} / \mathrm{s})$ & STD (\%) & $\mathrm{SCR}(\mathrm{g} / \mathrm{s})$ & STD (\%) \\
\hline 1 & 22.4 & 10.2 & 21.9 & 9.20 \\
\hline 2 & 34.9 & 5.80 & 32.1 & 7.40 \\
\hline 3 & 6.61 & 10.1 & 5.71 & 7.80 \\
\hline 4 & 19.4 & 10.1 & 19.3 & 7.60 \\
\hline 5 & 25.1 & 14.2 & 25.5 & 13.5 \\
\hline 6 & 23.7 & 10.7 & 26.9 & 9.50 \\
\hline 7 & 33.0 & 10.2 & 35.1 & 11.5 \\
\hline 8 & 20.1 & 10.5 & 21.1 & 7.90 \\
\hline 9 & 23.9 & 10.2 & 23.5 & 8.70 \\
\hline 10 & 28.3 & 5.80 & 25.1 & 8.30 \\
\hline 11 & 20.4 & 11.0 & 17.7 & 11.2 \\
\hline 12 & 27.0 & 11.0 & 24.3 & 11.0 \\
\hline 13 & 34.1 & 3.10 & 32.1 & 5.20 \\
\hline 14 & 8.27 & 9.20 & 8.02 & 3.10 \\
\hline 15 & 10.7 & 7.40 & 10.9 & 6.20 \\
\hline 16 & 14.9 & 9.10 & 13.4 & 6.71 \\
\hline 17 & 5.99 & 6.51 & 5.93 & 6.07 \\
\hline 18 & 6.65 & 5.26 & 6.46 & 2.63 \\
\hline 19 & 8.38 & 4.29 & 8.36 & 4.42 \\
\hline
\end{tabular}
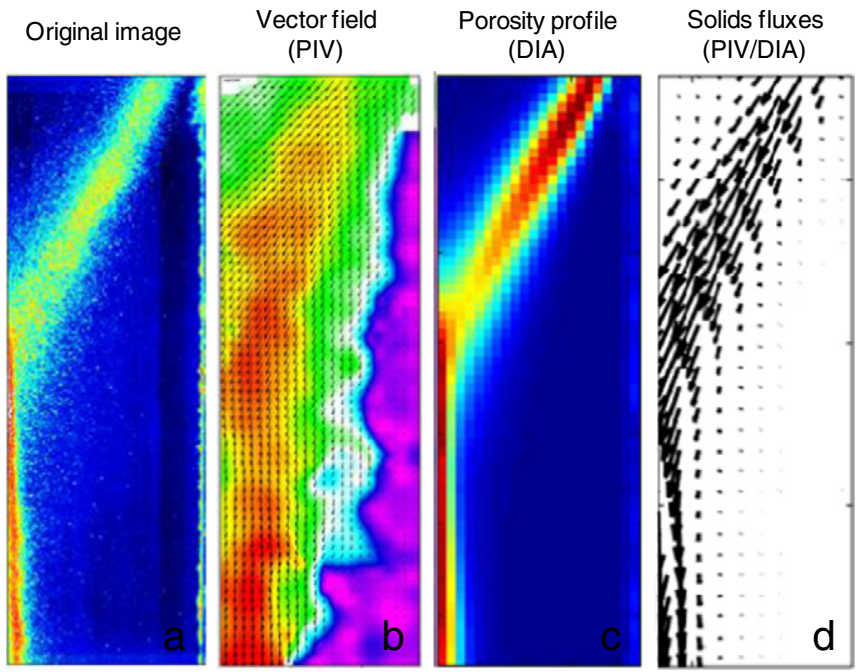

Fig. 4. Determination of the solid fluxes using the optical technique from instantaneous images; a) original image; b) vector field obtained using DaVis; c) 3D porosity profile of the original image after DIA analysis; d) solid fluxes corresponding to the original image.

in the riser column, whereas the inlet gas velocity in the fuel columns hardly modify the amount of solids transferred from the riser to the fuel columns. Furthermore, it can also be observed that the SCRs are decreased for non-spherical particles as a consequence of the reduced minimum fluidization velocity due to the higher contact surface area (i.e. increased drag coefficients). The results of the first five experiments are subsequently used for the determination of the $2 \mathrm{D}$ to $3 \mathrm{D}$ conversion factor when using PIV/DIA. On the other side, the pressure drop method does not require calibration and a direct determination of the SCR can be achieved knowing all the other variables of the system.

\subsection{Experimental solids circulation rates by PIV/DIA}

As explained in Section 2.2.2, a window area has been applied to the 2D column where the solids in the fuel columns move downwards from the top of the riser column. The window helps determining the SCR, especially with PIV approach, where particles are moving in one direction

Table 4

Summary of the SCR measured using the optical technique for all the experiments and the deviation observed compared to the method based on collecting particles.

\begin{tabular}{|c|c|c|c|c|c|c|}
\hline \multirow[b]{2}{*}{ Experiment } & \multicolumn{3}{|c|}{ Solid circulation rates $(\mathrm{g} / \mathrm{s})$} & \multicolumn{3}{|c|}{$\begin{array}{l}\text { Deviation to collected } \\
\text { particles (\%) }\end{array}$} \\
\hline & Left & Right & Riser & Left & Right & Riser \\
\hline 1 & 20.7 & 18.8 & 39.5 & 7.50 & 14.1 & 15.3 \\
\hline 2 & 27.9 & 28.3 & 56.2 & 20.1 & 11.8 & 21.2 \\
\hline 3 & 7.4 & 6.10 & 13.5 & 11.9 & 6.80 & 13.9 \\
\hline 4 & 21.0 & 21.4 & 42.4 & 8.13 & 11.0 & 12.8 \\
\hline 5 & 26.0 & 25.2 & 51.2 & 3.50 & 1.11 & 5.90 \\
\hline 6 & 27.0 & 26.6 & 53.6 & 13.7 & 1.12 & 15.9 \\
\hline 7 & 29.4 & 33.5 & 62.9 & 10.9 & 4.58 & 12.4 \\
\hline 8 & 22.4 & 20.7 & 43.1 & 9.8 & 2.48 & 11.7 \\
\hline 9 & 24.5 & 22.9 & 47.4 & 5.19 & 2.72 & 4.23 \\
\hline 10 & 25.6 & 23.6 & 49.2 & 9.70 & 5.90 & 10.8 \\
\hline 11 & 21.2 & 20.1 & 41.1 & 3.43 & 12.9 & 15.6 \\
\hline 12 & 24.6 & 25.9 & 50.5 & 8.85 & 6.60 & 9.27 \\
\hline 13 & 33.5 & 31.6 & 65.1 & 1.82 & 1.66 & 3.21 \\
\hline 14 & 9.30 & 9.10 & 16.3 & 15.9 & 10.0 & 16.8 \\
\hline 15 & 12.2 & 13.0 & 25.2 & 12.7 & 18.2 & 22.9 \\
\hline 16 & 17.1 & 15.4 & 28.4 & 14.1 & 14.6 & 18.4 \\
\hline 17 & 6.70 & 7.10 & 12.5 & 12.9 & 19.6 & 4.79 \\
\hline 18 & 6.90 & 7.40 & 14.3 & 6.71 & 14.4 & 9.03 \\
\hline 19 & 9.30 & 9.60 & 18.5 & 11.2 & 14.8 & 10.5 \\
\hline
\end{tabular}


and solids velocities can be better determined by cross correlation methods as compared to the solids motion in a riser reactor (more turbulent flow). Although a single recording is carried out to cover the whole window, post-processing of the data has been split into two different sections. One concerns the fuel columns, while the second one is related to the hydrodynamics in the riser. For all cases, 4000 images have been recorded to ensure representative time-averaged results.

The determination of the SCR in the fuel columns is depicted in Fig. 4 where the whole procedure is summarized. First the vector field (Fig. 4 b) is determined from the original image (Fig. 4 a) using cross correlation methods in DaVis. Subsequently, the original images are analyzed using DIA. Inhomogeneous ilumination is corrected for by subtraction of the background image (as explained in Section 2.2.2) and the normalized 2D intensity is converted to 3D porosity (Fig. 4 c) using the linear correlation given in Eq. (1). Finally the solid fluxes are determined by multiplying the instantaneous velocity field with the corresponding instantaneous porosity field (Fig. $4 \mathrm{~d}$ ).

The SCR are calculated by integrating the solid fluxes over the area, representing the amount of solids transferred from the riser to the fuel column per unit of time (in $\mathrm{g} / \mathrm{s}$ ). For the riser, the SCR are calculated by the average of the positive solids fluxes (typically in the center of the riser). Results of the experiments are summarized in Table 4. It can be observed that the optical technique gives accurate results for SCR for all the experiments, either in the fuel and riser columns. For all the cases the maximum deviation is around $20 \%$ typically for low SCR (which are most affected by experimental errors). However, an average of around $10 \%$ deviation has been measured for all the cases studied for both spherical and non-spherical particles.

Symmetry of the SCR has been assessed when comparing the solid flux profiles obtained for the three different columns of the reactor. For instance, Fig. 5 shows the solid fluxes as a function of the lateral position in correspondence to the window). In this figure, the solids fluxes at this axial position are compared for the first three experiments. Furthermore, it is also observed that the sum of all negative solids fluxes corresponding to the fuel columns is compensated by the sum of all positive fluxes measured in the riser column, which is related to the SCR mass balance in these types of reactors.

\subsection{Experimental solids circulation rates by the pressure drop method}

The average pressure drop over the riser has been measured for the different cases considered in this work. The total pressure drop in the riser, i.e. bottom to the top of the reactor, is used for the numerical analysis of the SCR in the riser using the approach described in Section 2.2.3. A typical profile of the pressure drop over the riser is depicted in Fig. 6 for the experiments using $500 \mu \mathrm{m}$ glass beads (experiments $1-5$ ). For

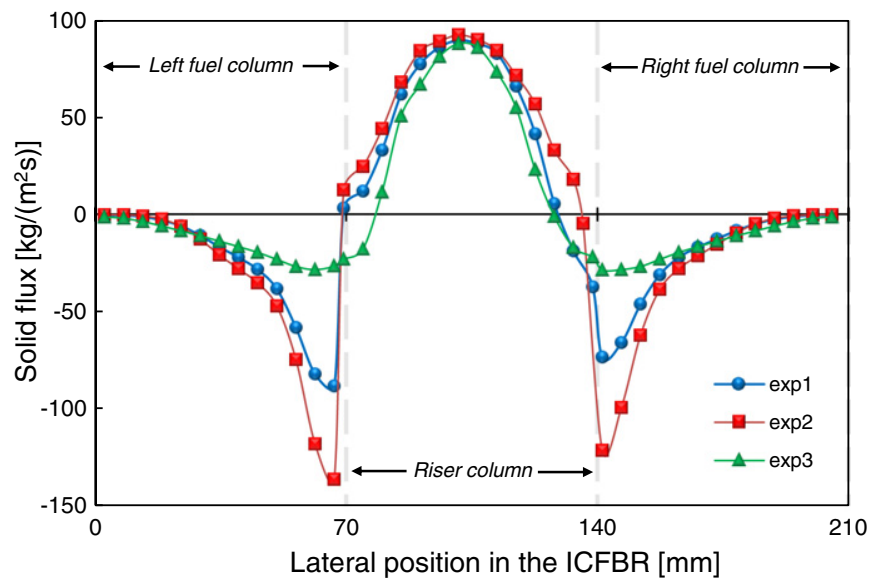

Fig. 5. Average solids flux profiles for experiments $1-3$ in the three columns using the optical technique.

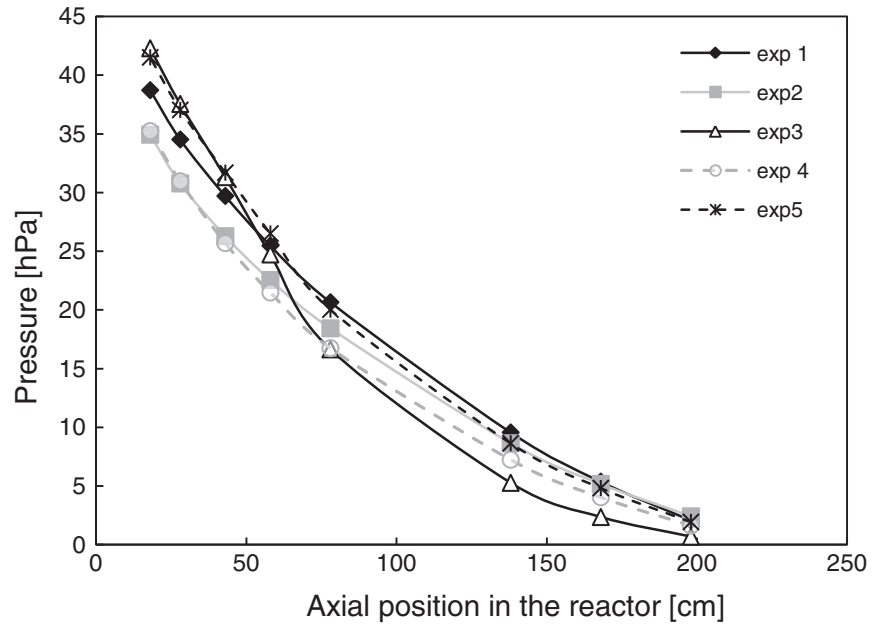

Fig. 6. Pressure drop profile over the riser column for experiments 1-5.

this set of experiments it can be noted that the highest pressure drop corresponds to the case with the lowest SCR as measured by particle collection. This trend is expected due to the denser region at the bottom (higher pressure drop) and much lower solids hold-up at the top (corresponding to low pressure difference). Also for other experiments, the pressure drops measured over the column correspond to the expected trends.

The SCR have been measured for each experiment once determined with the total pressure drop measured over the riser column and once calculated with the computed terminal velocity with the corresponding particle properties (Eqs. (2) to (14)). A summary of the results including the standard deviation is presented in Table 5. Results show that the SCR can be well predicted using this method. This method has been successfully applied for spherical particles, whereas it also gives good estimations for non-spherical particles, which are most likely used in industrial processes. The pressure drop and the optical methods have in common that they are relatively cheap and that after a first calibration (for the optical technique), maintenance is not required.

\subsection{Comparison of the three different experimental methods}

The SCR have been investigated in the literature through many different methods for circulating beds. However, there is no agreement on the method that compromises accuracy, durability and costs. In

Table 5

Summary of the SCR determined using the pressure drop method for all the experiments and their deviation compared to the method based on particle collection.

\begin{tabular}{lcc}
\hline Experiment & Solid circulation rates $(\mathrm{g} / \mathrm{s})$ & Deviation to collected particles $(\%)$ \\
\hline 1 & 47.3 & 6.79 \\
2 & 55.2 & 17.4 \\
3 & 15.1 & 23.2 \\
4 & 40.1 & 3.59 \\
5 & 47.4 & 6.42 \\
6 & 51.4 & 1.53 \\
7 & 63.6 & 6.53 \\
8 & 44.0 & 6.64 \\
9 & 50.9 & 8.67 \\
10 & 53.9 & 0.95 \\
11 & 37.0 & 3.00 \\
12 & 47.9 & 6.50 \\
13 & 57.3 & 13.4 \\
14 & 16.6 & 1.78 \\
15 & 26.2 & 3.93 \\
16 & 31.6 & 12.1 \\
17 & 12.9 & 8.40 \\
18 & 14.1 & 7.58 \\
19 & 17.6 & 5.30 \\
\hline
\end{tabular}




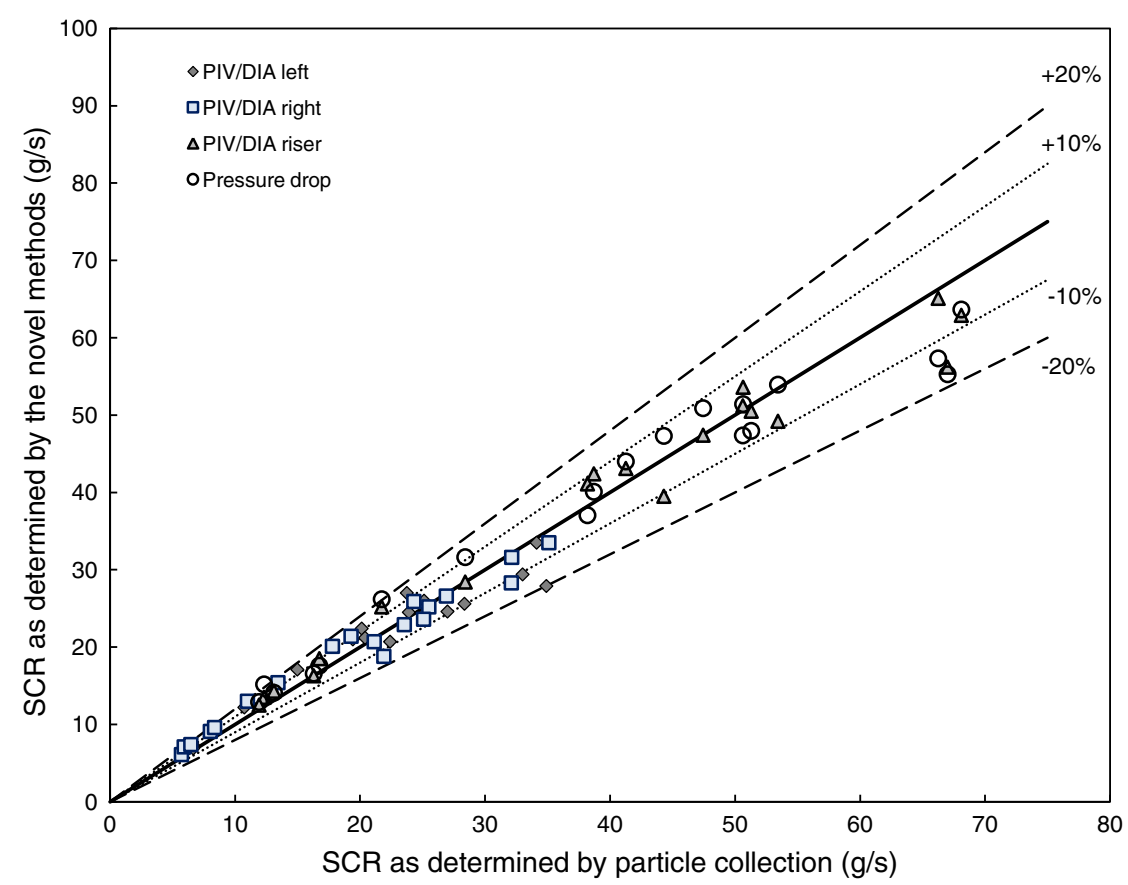

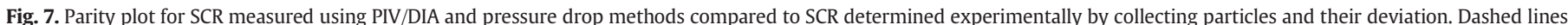
represent the deviations in the measurements.

this study two of the main methods proposed in the literature are used and are compared to a novel third method based on optical techniques. A parity plot with the comparison of the three methods is depicted in Fig. 7. From this figure it is observed that a narrow deviation over the measured SCR by collecting particles is obtained by the other two novel methods, hence implying a good accuracy for the prediction of the SCR. This is of special interest because both the optical technique and the pressure drop method are non-intrusive methods and the hydrodynamics of the system are not affected, which means that the SCR can be continuously monitored, contrary to the typical particle collection method.

Furthermore, the average solids hold-up in the riser can be measured using the pressure drop method between two positions in the riser. The optical technique also allows to measure porosities in the

\section{Table 6}

Average solids hold-up measured in the riser column using the PIV/DIA and the pressure drop methods for all the experiments in this work.

\begin{tabular}{lcc}
\hline Experiment number & PIV/DIA method & Pressure drop method \\
\hline 1 & 0.0247 & 0.0227 \\
2 & 0.0187 & 0.0140 \\
3 & 0.0279 & 0.0354 \\
4 & 0.0239 & 0.0214 \\
5 & 0.0259 & 0.0252 \\
6 & 0.0257 & 0.0266 \\
7 & 0.0272 & 0.0303 \\
8 & 0.0581 & 0.0510 \\
9 & 0.0622 & 0.0550 \\
10 & 0.0634 & 0.0560 \\
11 & 0.0382 & 0.0405 \\
12 & 0.0340 & 0.0360 \\
13 & 0.0283 & 0.0325 \\
14 & 0.0247 & 0.0227 \\
15 & 0.0187 & 0.0140 \\
16 & 0.0279 & 0.0354 \\
17 & 0.0253 & 0.0224 \\
18 & 0.0257 & 0.0231 \\
19 & 0.0321 & 0.0284
\end{tabular}

riser after background correction and both can be compared. As summarized in Table 6 there is also a good agreement in terms of solids hold-up when using the two different methods. Moreover, these values are in good agreement with typical measured hold-up values reported in the literature $[7,24]$.

\section{Conclusions}

Three different experimental methods for the measurement of solids circulation rates in a pseudo 2D internally circulating column have been studied and compared in this work. The SCRs measured with the three methods lead to similar results within 20\% maximum deviation (and most of them within 10\%) for the different experimental conditions studied in this work: combination of several particle properties (density, diameter and sphericity), solids inventories and superficial gas velocities were analyzed.

The optical method has been successfully developed by fine tuning (using few experiments) and then applying to all the experiments a linear relationship between the images and 3D solids hold-ups. This method works well for the three columns in the 2D ICFB system and good symmetry in the solids circulation patterns has been obtained. Moreover, the measured solids hold-up values are in a good agreement with the literature and also with the pressure drop method used in this work. The pressure drop method is based on the Richardson and Zaki approach in the Bernoulli equation. Good accuracy also for nonspherical particles was found after adjustment of the terminal velocity. This method can be of interest since industry commonly uses nonspherical particles. For the optical technique non-sphericity does not pose a problem as it is based on cross-correlation of intensity profiles.

The two novel methods have been developed and validated in this work for cold flow measurements. They do not require expensive maintenance and can be used continuously in circulating systems without any influence on the hydrodynamics. However, in this work the experiments have been carried out at room temperature and the methods should also be validated at elevated temperatures and, for the pressure drop method, also for 3D systems. 


\section{Nomenclature}

\begin{tabular}{lll}
\hline$a$ & Width of the column & $\mathrm{m}$ \\
$A$ & Constant value for correlation 2D-3D porosity & - \\
$A_{c}$ & Section of the riser column & $\mathrm{m}^{2}$ \\
$b$ & Depth of the column & $\mathrm{m}$ \\
$C_{D}$ & Drag coefficient & - \\
$D$ & Hydraulic diameter of the column & $\mathrm{m}$ \\
$d_{p}$ & Particle diameter & $\mathrm{m}$ \\
$d_{p}{ }^{*}$ & Dimensionless Particle diameter & - \\
$F_{i}$ & Inlet gas flow rate & $\mathrm{Ln} / \mathrm{min}$ \\
$f$ & Darcy frictional factor & - \\
$g$ & Gravitational constant & $\mathrm{m} / \mathrm{s}^{2}$ \\
$n$ & Exponential factor & - \\
$p$ & Pressure & $\mathrm{Pa}$ \\
$R e$ & Reynolds number & - \\
$\mathrm{SCR}$ & Solids circulation rates & $\mathrm{g} / \mathrm{s}$ \\
$\mathrm{SI}$ & Solids Inventory & $\mathrm{kg}$ \\
$u_{g}$ & Superficial gas velocity & $\mathrm{m} / \mathrm{s}$ \\
$u_{p}$ & Particle velocity & $\mathrm{m} / \mathrm{s}$ \\
$u_{t}$ & Particle terminal velocity & $\mathrm{m} / \mathrm{s}$ \\
$u_{t}{ }^{*}$ & Dimensionless Particle terminal velocity & - \\
\hline
\end{tabular}

\section{Greek letters}

\begin{tabular}{lll}
\hline$\varepsilon_{2 D}$ & 2D intensity from image & - \\
$\varepsilon_{3 D}$ & 3D solids hold-up (PIV/DIA method) & - \\
$\varepsilon_{\mathrm{s}}$ & Solids hold-up (pressure drop method) & - \\
$\varepsilon_{g}$ & Bed porosity & - \\
$\lambda$ & Roughness of anodized aluminum & $\mathrm{m}$ \\
$\mu_{g}$ & Dynamic viscosity of the gas & $\mathrm{Pa} \cdot \mathrm{s}$ \\
$\rho_{g}$ & Gas density & $\mathrm{kg} / \mathrm{m}^{3}$ \\
$\rho_{R}$ & Density in the riser & $\mathrm{kg} / \mathrm{m}^{3}$ \\
$\rho_{\mathrm{s}}$ & Particle density & $\mathrm{kg} / \mathrm{m}^{3}$ \\
$\emptyset$ & Sphericity & - \\
\hline
\end{tabular}

\section{Acknowledgments}

NWO/STW is acknowledged for the financial support through the VIDI project number 12365 .

\section{References}

[1] IPCC, IPCC Special Report on Carbon Dioxide Capture and Storage, Cambridge University Press, Cambridge, UK, 2005.

[2] IPCC, Climate Change 2014: Synthesis Report, Contribution of Working Groups I, Il and III to the Fifth Assessment Report of the Intergovernmental Panel on Climate Change, 2014

[3] IEA, Energy Technology Perspectives: Scenarios and Strategies to 2050, OECD/IEA, Paris, France, 2010

[4] J.D. Holladay, J. Hu, D.L. King, Y. Wang, An overview of hydrogen production technologies, Catal. Today 139 (2009) 244-260.

[5] S. Dunn, Hydrogen futures: toward a sustainable energy system, Int. J. Hydrog. Energy 27 (2002) 235-264
[6] J.A. Swaffield, S. Bridge, Applicability of the Colebrook-White formula to represent frictional losses in partially filled unsteady pipeflow, J. Res. Natl. Bur. Stand. 88 (1983) (1934) 389-393.

[7] C. Wang, High Density Gas-solids Circulating Fluidized Bed Riser and Downer reactors, 2013.

[8] M. Wang, A. Lawal, P. Stephenson, J. Sidders, C. Ramshaw, Post-combustion $\mathrm{CO}_{2}$ capture with chemical absorption: a state-of-the-art review, Chem. Eng. Res. Des. 89 (2011) 1609-1624.

[9] S.A.R.K. Deshmukh, S. Heinrich, L. Mörl, M. van Sint Annaland, J.A.M. Kuipers, Membrane assisted fluidized bed reactors: potentials and hurdles, Chem. Eng. Sci. 62 (2007) 416-436.

[10] F. Gallucci, E. Fernandez, P. Corengia, M. van Sint Annaland, Recent advances on membranes and membrane reactors for hydrogen production, Chem. Eng. Sci. 92 (2013) 40-66.

[11] L. Roses, F. Gallucci, G. Manzolini, M. van Sint Annaland, Experimental study of steam methane reforming in a Pd-based fluidized bed membrane reactor, Chem. Eng. J. 222 (2013) 307-320.

[12] J.A. Medrano, V. Spallina, M. van Sint Annaland, F. Gallucci, Thermodynamic analysis of a membrane-assisted chemical looping reforming reactor concept for combined $\mathrm{H}_{2}$ production and $\mathrm{CO}_{2}$ capture, Int. J. Hydrog. Energy 39 (2014) 4725-4738.

[13] M. Gazzani, D.M. Turi, G. Manzolini, Techno-economic assessment of hydrogen selective membranes for $\mathrm{CO}_{2}$ capture in integrated gasification combined cycle, Int. J. Greenh. Gas Control 20 (2014) 293-309.

[14] G. Di Marcoberardino, L. Roses, G. Manzolini, Technical assessment of a micro-cogeneration system based on polymer electrolyte membrane fuel cell and fluidized bed autothermal reformer, Appl. Energy 162 (2016) 231-244.

[15] A. Lyngfelt, Chemical-looping combustion of solid fuels - status of development, Appl. Energy 113 (2013) 1869-1873.

[16] J. Adanez, A. Abad, F. Garcia-Labiano, P. Gayan, L.F. de Diego, Progress in chemicallooping combustion and reforming technologies, Prog. Energy Combust. Sci. 38 (2012) 215-282.

[17] M. Ishida, $\mathrm{H}$. Jin, A new advanced power-generation system using chemical-looping combustion, Energy 19 (1994) 415-422.

[18] Y.A. Alghamdi, E. Doroodchi, B. Moghtaderi, Mixing and segregation of binary oxygen carrier mixtures in a cold flow model of a chemical looping combustor, Chem. Eng. J. 223 (2013) 772-784.

[19] S. Matsuda, Measurement of solid circulation rate in a circulating fluidized bed, Powder Technol. 187 (2008) 200-204.

[20] J. Liu, J.R. Grace, X. Bi, Novel multifunctional optical-fiber probe: I. Development and validation, AIChE J. 49 (2003) 1405-1420.

[21] J.X. Zhu, G.Z. Li, S.Z. Qin, F.Y. Li, H. Zhang, Y.L. Yang, Direct measurements of particle velocities in gas-solids suspension flow using a novel five-fiber optical probe, Powder Technol. 115 (2001) 184-192.

[22] J.C. Ludlow, E.R. Monazam, L.J. Shadle, Improvement of continuous solid circulation rate measurement in a cold flow circulating fluidized bed, Powder Technol. 182 (2008) 379-387.

[23] D.C. Guío-Pérez, G. Tondl, W. Höltl, T. Pröll, H. Hofbauer, Cold flow model study of an oxyfuel combustion pilot plant, Chem. Eng. Technol. 34 (2011) 2091-2098.

[24] Y. Alghamdi, Z. Peng, K. Shah, B. Moghtaderi, E. Doroodchi, Predicting the solid circulation rate in chemical looping combustion systems using pressure drop measurements, Powder Technol. 286 (2015) 572-581.

[25] A. Haider, O. Levenspiel, Drag coefficient and terminal velocity of spherical and nonspherical particles, Powder Technol. 58 (1989) 63-70.

[26] J.F. De Jong, S.O. Odu, M.S. Van Buijtenen, N.G. Deen, M. Van Sint Annaland, J.A.M. Kuipers, Development and validation of a novel digital image analysis method for fluidized bed particle image velocimetry, Powder Technol. 230 (2012) 193-202.

[27] S. Mahmoudi, J. Baeyens, J. Seville, The solids flow in the CFB-riser quantified by single radioactive particle tracking, Powder Technol. 211 (2011) 135-143.

[28] H. Scott Fobler, Elements of chemical reaction engineering, 4th ed, 2005.

[29] J. N.Tilton, Fluid and Particles Dynamics, 8th ed., 2008.

[30] J.R. Sonnad, C.T. Goudar, Explicit reformulation of the Colebrook-White equation for turbulent flow friction factor calculation, Ind. Eng. Chem. Res. 46 (2007) 2593-2600.

[31] R. Turton, N.N. Clark, An explicit relationship to predict spherical particle terminal velocity, Powder Technol. 53 (1987) 127-129. 